\title{
REFORMA CURRICULAR DE GRADUAÇÃO EM ENFERMAGEM - ESCOLA DE ENFERMAGEM DE RIBEIRÃO PRETO - UNIVERSIDADE DE SÃO PAULO
}

\author{
Comissão de Reestruturação Curricular da
} Escola de Enfermagem de Ribeirão Preto/USP*

O presente estudo tem como propósito a descrição do processo de reforma curricular do curso de graduação, desenvolvido pela Escola de Enfermagem de Ribeirão Preto da Universidade de São Paulo observando-se as etapas do planejamento curricular: o diagnóstico, os objetos educacionais, seleção e organização curricular, estratégias curriculares e avaliação curricular.

Face a um diagnóstico da realidade vigente a necessidade da formação do enfermeiro generalista, apresenta-se um conceitual direcionado a visão do homem, comunidade, processo saúde-doença, enfermagem, enfermeiro generalista, competência e currículo. Propõe-se o fortalecimento do ensino das ciências biológicas e humanas do ciclo básico bem como dos aspectos administrativos nas atividades sanitárias e hospitalares. Esse currículo abrange os ciclos de formação pré-profissional e profissional a serem oferecidos em oito semestres do curso de graduação da Escola de Enfermagem de Ribeirão Preto da Universidade de São Paulo.

\section{1 - Introdução}

As Mudanças ocorridas na enfermagem nas últimas décadas na América Latina e, sobretudo no Brasil trouxeram a necessidade de uma revisão do ensino e do perfil

\footnotetext{
*Coordenação da Comissão: Profa Dra. Dulce Maria Vendrúscolo de Freitas.

Composição: Prof as. Dras. Branca Maria de Oliveira Santos; Dulce Maria Vendrúsculo de Freitas; Edna Paciência Vietta; Elizabeth Laus Ribas Gomes; Elizabeth Ranier Martins do Valle; Iranilde José Messias Mendes; Lisete Diniz Ribas Casagrande; Márcia Caron Ruffino; Maria Solange Guarino Tavares; Margarida Antonia Villar Luis; Rosalina Aparecida Partezani Rodrigues; Silvana Martins Mishima e Sonia Maria Villela Bueno.
} 
profissional, buscando adequar a formação do enfermeiro à realidade social de cada região e a organização do setor saúde.

Nesse período, o Sistema de Saúde Brasileiro passava por importantes transformações de caráter econômico e político, culminado com propostas de mudanças do modelo de assistência vigente, centrado nos aspectos curativos.

Vale lembrar que, na década de 80, ocorreu o Processo de Reforma Sanitária, tendo como ponto máximo $8^{a}$ Conferência Nacional de Saúde que preconizou a unificação do Sistema de Saúde através de descentralização e hierarquização da assistência pelo sistema de referência e contra-referência. Com a implantação desse novo modelo, o profissional de enfermagem passou a atuar nas áreas da assistência ao adulto, à mulher e à criança, nos diferentes níveis de atenção: primária, secundária e terciária.

Em decorrência dessa reorganização do Setor Saúde, iniciou-se também o processo de municipalização da assistência ampliando, em alguns principais municípios brasileiros, a oferta de trabalho aos enfermeiros na área da saúde pública, requerendo uma formação profissional voltado para o atendimento das necessidades de saúde coletiva e individual da população.

Essas mudanças vem reforçar a necessidade de uma reformulação curricular a nível de graduação, levando a Escola de Enfermagem de Ribeirão Preto da Universidade de São Paulo/EERP-USP, iniciar, com a instituição de uma Comissão de Reestruturação Curricular, um estudo e uma revisão do seu currículo, procurando responder às exigências para formação do profissional enfermeiro.

O objetivo deste trabalho é, portanto descrever o processo de reforma curricular da EERP-USP, provado e implantando em 1989, que trouxe como proposta a formação do enfermeiro generalista, adequando seu ensino às mudanças ocorridas no Setor Saúde.

\section{Alguns aspectos históricos da EERP-USP}

A Escola de Enfermagem de Ribeirão Preto da Universidade de São Paulo foi criada, anexa à Faculdade de Medicina de Ribeirão Preto da Universidade de São Paulo, pela Lei Estadual n. ${ }^{0}$ 1467, 26 de dezembro de 1951 com o desafio de formar profissionais tanto para prestar assistência de enfermagem como para dirigir unidades de enfermagem em Hospitais e Centros de Assistência à Saúde, incluindo nessas funções, o ensino e a supervisão de pessoal auxiliar.

Com a autorização de funcionamento do Curso de Enfermagem em 08 de maio de 1954, pela Portaria n. ${ }^{\circ} 265$ do Ministério Educação e Cultura/MEC, o referido curso passou a ser reconhecido, em 1957, através do Decreto Lei n. ${ }^{\circ} 42.812$ de 13 de Dezembro.

Em 24 de novembro de 1960, foi promulgada a Lei Estadual n. 5970 que dispunha sobre a estrutura didática e administrativa de Escola, designando-a como estabelecimento de ensino de nível superior. 
Com base no parecer 271/62 do Conselho Federal de Educação, sobre o Currículo Mínimo dos Cursos de Graduação em Enfermagem, esta Escola ofereceu, no período de 1953 a 1966, o curso de Enfermagem Geral, com duração de 4 anos. A partir de 1967, o curso passou a ter duração de 3 anos e mais um ano opcional de curso de Enfermagem de Saúde Pública.

Na década de 70, a Escola de Enfermagem de Ribeirão Preto da Universidade de São Paulo passa a receber influências internas e externas que repercutiram no ensino de graduação, tais como: a Reforma Universitária, as alterações na Legislação do Ensino Superior e o Parecer 163/72 do Conselho Federal de Educação instituindo o Currículo Mínimo dos Cursos de Graduação em Enfermagem, subdividindo-o em 3 ciclos: préprofissional, profissional e as habilitações.

Como decorrência desses instrumentos legais, a Escola sobre modificações importantes na sua estrutura acadêmica e a administrativa, podendo-se destacar a inclusão das habilitações em Enfermagem de Saúde Pública, Enfermagem Médico-Cirúrgia e, a seguir, Enfermagem Obstétrica, em 1973, instituição do sistema de crédito, de matrículas semestrais e dos vestibulares unificados, fixação do número de vagas para 80 alunos, exigência da carreira universitária para seus docentes, instalação de sua Congregação e criação dos Departamentos de Enfermagem Geral e Especializada e Departamento de Enfermagem Psiquiátrica e Ciências Humanas.

A partir de 1980, a Escola amplia-se como centro de formação profissional, voltado não somente para o Curso de Graduação, mas também para os de Pós-Graduação. Seu corpo docente e discente se defronta com uma série de questionamentos inerentes à formação profissional; neste período avolumavam-se discussões que apontavam para a necessidade de mudanças curriculares ${ }^{11}$.

Naquela década, a Escola de Enfermagem de Ribeirão Preto da Universidade de São Paulo inicia estudos com vistas a uma nova proposta curricular, procurando atender às exigências demandadas pelo exercício das funções do profissional enfermeiro. A necessidade de reforma do currículo de graduação era captada não só ao nível da Escola, mas também a nível nacional, sendo amplamente discutida através do posicionamento das Instituições de Ensino, e dos órgãos de classe ${ }^{2,4}$.

\section{II - Currículo: quadro conceitual}

Para tratar da reforma curricular, foi estabelecida uma seqüência de decisões sobre o currículo de Enfermagem, que tornasse efetiva sua modificação. Para tanto foi criada a Comissão de Reestruturação Curricular, em 1979, que partiu do princípio de que o currículo de formação profissional, mais que "um rol de disciplinas, é o conjunto de matérias, modos e 
meios de ensino-aprendizagem decorrentes do contexto cultural e da natureza da área de conhecimento envolvida, que assumem a configuração de disciplinas a serem desenvolvidas, cooperativamente, por professores e alunos, visando ao desenvolvimento da competência para o exercício da profissão"10.

A reformulação no currículo de graduação implica em revisão do próprio conceito da profissão, da definição de seu objeto, de sua metodologia de trabalho e do perfil do profissional. Para tanto, explicitam-se os seguintes pressupostos:

- O currículo envolve tanto o conteúdo a ser aprendido, como o modelo pelo qual este será ensinado; portanto, a metodologia e as técnicas de ensino empregadas, também fazem parte do currículo;

- O contexto cultural é reflexo dos contextos social, político, econômico, religioso e histórico; é nele que se insere o exercício das diversas profissões. Assim como em outras profissões, na enfermagem, também o contexto cultural é o fator determinante de sua definição como prática social $^{1}$;

- A matéria de ensino precisa ser selecionada, seqüenciada, apresentada aos alunos de forma adequada ao seu nível de compreensão, de modo a facilitar a integração entre teoria e prática;

- O desenvolvimento do currículo de formação profissional é efetuado através da interação professor-aluno, na sala de aula, no campo de ensino prático e em atividades conjuntas de pesquisas;

- A matéria de ensino precisa ser seleciona, seqüenciada, apresentada aos alunos de forma adequada ao nível de compreensão, de modo a facilitar a integração entre teoria e prática;

- O desenvolvimento do currículo de formação profissional é efetuado através da interação professor-aluno, na sala de aula, no campo de ensino prático e em atividades conjuntas de pesquisa;

- A competência é o resultado que se espera atingir, ao longo do desenvolvimento de um currículo de formação profissional. A competência profissional envolve o saber, como este se aplica á solução de problemas da profissão e a postura do profissional face ao seu exercício. Numa perspectiva piagetiana, entende-se por competência a aquisição e o desenvolvimento de estruturas cognitivas que o indivíduo usa na organização do mundo que ele percebe ${ }^{10}$. Um indivíduo competente constrói estruturas mentais no sentido de resolver problemas de forma eficiente, criativa e inteligente. Este é um conceito aberto à formação do indivíduo como profissional operando no meio social e à adequação da profissão, enquanto resposta às necessidades sociais. A competência não se restringe, portanto a execução de tarefas pré-determinadas.

Sendo o currículo um dos caminhos para a viabilização dessa competência profissional, os resultados obtidos durante o período de graduação dependem de uma organização e desenvolvimento eficientes, revertendo-se num processo de formação a longo prazo. O curso de graduação é a primeira etapa sistematizada, do processo de formação profissional que poderá continuar por toda a vida produtiva do indivíduo.

A profissão de enfermagem tem se pautado no desenvolvimento de atividades que visam à promoção, proteção e recuperação da saúde do indivíduo e da coletividade. Para a realização dessas atividades pressupõe-se o relacionamento com o homem sadio e o docente, o domínio do saber específico no que tange a assistência à saúde da população e o 
compromisso de participação social.

Frente aos diferentes conceitos da enfermagem entendida como, arte, técnica, ciência ou prática social, considera-se que esses são pertinentes, permeando o saber e a prática profissional como um todo, devendo ser abordadas dentro da realidade social, sem que haja super valorização de uma dessas concepções, em detrimento de outra ${ }^{1,5}$.

Tais reflexões orientaram a Comissão de Reestruturação Curricular na proposta de reformulação voltada para a formação do enfermeiro generalista com potencial para global, integrada e crítica sendo esta a linha orientadora para o ensino compatível com experiências de aprendizagem, nas quais o desempenho do aluno pressupõe fundamentação teórica para a sua atuação nos serviços de saúde e em diferentes níveis de complexidade. Esta formação generalista implica no desenvolvimento de competência técnico-científica e política à solução de problemas da profissão e à postura do profissional face ao exercício da mesma. Tal postura decorre de uma reflexão crítica acerca do homem, da sociedade e do processo saúde-doença.

Nesse enfoque, a proposta de formação do enfermeiro generalista pressupõe uma abordagem multidisciplinar, fundamentada nas ciências humanas, biológicas e, sobretudo, embasada em alguns princípios filosóficos. Acredita-se que esta visão voltada para o enfermeiro generalista enriquece e fortalece a formação profissional propiciando melhor desempenho.

\section{III - Modelo de planejamento curricular: desenvolvimento das etapas.}

Para nortear a proposta de trabalho apresentada pela Comissão de Reestruturação Curricular, utilizou-se o Modelo de Planejamento Curricular ${ }^{12}$, que compreende um conjunto de cinco etapas a serem seguidas: diagnóstico das necessidades, objetivos educacionais, seleção e organização do conteúdo, organização curricular, estratégias curriculares e avaliação, explicitadas a seguir.

\section{Diagnóstico das necessidades}

Com a finalidade de se obter subsídios para a elaboração do diagnóstico das necessidades exigidas pelo ensino de graduação, realizou-se uma série de eventos e estudos organizados pela Comissão de Ensino da Escola de Enfermagem de Ribeirão Preto da 
Universidade de São Paulo. Nesta fase, que se estendeu de 1979 a 1985, foram discutidas as seguintes temáticas: revisão de princípios filosóficos norteadores do currículo da Escola de Enfermagem de Ribeirão Preto da Universidade de São Paulo, definição das funções pertinentes para o trono pré-profissional capaz de promover integração entre as disciplinas, proposta de retirada das habilitações com a finalidade de formar enfermeiro generalista e ainda, as várias abordagens da profissão de enfermagem. As discussões decorrentes desse processo apoiam-se basicamente no Seminário "A prática da enfermagem e o currículo de graduação", cuja temática serviu para subsidiar a proposta do novo currículo. O "Relatório sobre os estudos da reforma curricular da Escola de Enfermagem de Ribeirão Preto da Universidade de São Paulo". elaborado pela Comissão de Estudos Curriculares em 1986, orientou a discussão nos várias colegiados e Departamentos da Escola ${ }^{5,6,8}$.

Outra preocupação foi a de identificar determinantes internos e externos à profissão de Enfermagem, que constituíssem marco referencial para o processo de reestruturação do currículo de graduação. Os elementos que nortearam estas discussões para a elaboração do diagnóstico foram:

- o mercado de trabalho do enfermeiro, que teve por fundamentação as funções exercidas pelo enfermeiro na prática profissional; a redefinição de funções e papéis, e a atualização da Lei do Exercício Profissional (Lei n. $\left.{ }^{\circ} 2604 / 55\right)$;

- a política nacional de recursos humanos em enfermagem, tanto a nível de serviços básicos de saúde como a nível de assistência hospitalar e a participação da Enfermagem no movimento da Reforma Sanitária que se inicia na década de 80 ;

- a revisão do atual currículo de graduação - Parecer 163/72 do Conselho Federal de Educação ${ }^{3}$, que estabelece três níveis de formação - ciclo pré-profissional, profissional e habilitações; estas habilitações levam a uma especialização precoce dentro do currículo de graduação, atendendo ao mercado de trabalho, centrado na assistência individual e curativa;

- a proposta de uma formação básica generalista do enfermeiro. Esta formação ocorre no ciclo profissional, acrescida ou não das habilitações previstas pelo Parecer 163/72 e da Licenciatura em Enfermagem. A possibilidade da inclusão das habilitações e especializações constitui um empreendimento a ser realizado posterior a formação do generalista.

Este diagnóstico reforçando a proposta de formação generalista envolve o posicionamento da EERP/USP frente às políticas de saúde do país e a necessidade do mercado de trabalho.

\section{Objetivos educacionais, seleção e organização do conteúdo}

Esses elementos compreendem a segunda e a terceira etapas do modelo de 
planejamento adotado. Foram tratados concomitantemente, pois ambos se relacionam à seleção e à organização de experiências de aprendizagem que se pretende oferecer ao aluno, através de uma proposta curricular.

Segundo Tyler ${ }^{14}$, existem três critérios principais que norteiam a organização das situações de aprendizagem e conseqüentemente, a elaboração dos objetos e do conteúdo disciplinar. São eles: - continuidade, seqüência e integração, que compõe os elementos essenciais da orientação vertical e horizontal da grade curricular. Através de uma proposta de integração vertical utilizando os critérios de continuidade e seqüência, foram delimitados dois ciclos curriculares: o de Formação Básica Pré-Profissional e o de Formação Profissional.

Estes foram definidos a partir da proposta de formação do enfermeiro generalista, suprimindo-se habilitações anteriores requeridas.

O ciclo Pré-Profissional compreende os principais gerais básicos num currículo de formação profissional para a área de saúde abrangendo o desenvolvimento das disciplinas que compõe o núcleo de ciências do comportamento, ciências biológicas, saúde da comunidade, princípios gerais da formação profissional e educação em saúde. A duração prevista deste ciclo foi viabilizada para quatro semestres, sendo a carga horária semestral em torno de 450 horas, não devendo ultrapassar a 30 horas de aulas formais por semana.

O ciclo profissional compreende uma seqüência de experiências de aprendizagem com vistas à formação básica do enfermeiro, capacitando-o ao desenvolvimento da assistência individual e coletiva dirigida à criança, à mulher e ao adulto nas áreas de enfermagens clínicas, cirúrgicas, obstétricas, ginecológica, pediatra e psiquiátrica. Abrangem três semestres letivos, cada um com carga horária prevista para 450 horas. No último semestre são oferecidos aos alunos experiências de aprendizagem mais complexas voltadas para a formação do enfermeiro generalista, capacitando-o atuar tanto na administração de serviços básicos, como na administração de serviços da rede hospitalar.

O terceiro critério citado por Tyler ${ }^{14}$, o de integração horizontal foi adotado pela Comissão, através da definição de Conceitos gerais amplos-eixos integradores; que norteiam, em cada unidade curricular, a definição dos objetivos gerais, a seleção e organização curricular. Esta integração proporcionará o desenvolvimento de experiências de aprendizagem, inserindo o aluno no contexto da saúde e da assistência de enfermagem, centrando esta assistência em níveis de complexidade crescentes.

Os critérios de integração horizontal do currículo compreendem os seguintes aspectos:

- elaboração de conceitos gerais relativos ao homem, ao processo saúde-doença e Enfermagem. Estes conceitos orientam a formulação dos objetivos e do conteúdo das áreas de conhecimento que compõem a grade curricular;

- reorientação dos conteúdos disciplinares, adequando-se aos conceitos básicos delineados pelos eixos integradores a níveis de complexidade crescentes, oferecendo maior clareza de objetivos e reorientando as experiências de aprendizagem a serem proporcionadas;

- integração disciplinar que ofereça subsídios para o ensino teórico-prático nos vários 
segmentos da comunidade, facilitando o processo ensino-aprendizagem através da inserção dos docentes e discentes nas instituições onde a Escola de Enfermagem atua.

\section{Organização e estratégias curriculares}

O esquema da organização curricular é apresentado a seguir.

\begin{tabular}{||l|ll||}
\hline CICLO PRÉ-PROFISSIONAL & \multicolumn{2}{|c|}{ CICLO PROFISSIONAL } \\
\hline \multirow{3}{*}{$1^{\circ}$ ao $4^{\circ}$ Semestre } & $5^{\circ}$ Semestre & $7^{\circ}$ Semestre \\
& Enfermagem de Saúde & Enfermagem \\
& Pública e Hospitalar & Hospitalar \\
\cline { 2 - 3 } & Enfermagem Hospitalar & Enfermagem \\
& & Hospitalar e \\
& & Sanitária \\
\hline
\end{tabular}

A relação entre os eixos integradores e os objetivos preconizados para ciclo préprofissional e profissional é apresentado nos quadros I, II e III, delineando-se a quarta etapa do modelo de planejamento adotado, ou seja, a organização curricular. Ao término dessa fase o documento sobre a proposta de Reforma Curricular foi encaminhada à Direção e demais Colegiados para apreciação e discussão.

A partir desse momento, o processo de reestruturação curricular passou a contar com a participação da Comissão de Graduação da EERP-USP e dos Departamentos, que completaram as etapas de Organização Curricular e Estratégias Curriculares.

Após amplo processo de discussão entre docentes e dissentes dos três Departamentos, trabalho este coordenado pela Comissão de Graduação da EERP/USP, no período de 1987-1988 foi elaborada a grade curricular do curso de graduação apresentada em anexo. 


\section{QUADRO I - Eixos Integradores o Objetivos do Ciclo Pré-Profissional}

\begin{tabular}{|l|l||}
\hline \multicolumn{1}{|c|}{ Eixos Integradores } & \multicolumn{1}{c|}{ Objetivos } \\
\hline $\begin{array}{l}\text { O homem como um todo bio-psico-social e } \\
\text { espiritual. }\end{array}$ & $\begin{array}{l}\text { Favorecer no desenvolvimento de uma atitude de respeito a } \\
\text { dignidade da pessoa humana, baseada na compreensão do } \\
\text { homem como unidade bio-psico-social em equilíbrio dinâmico } \\
\text { com o seu meio ambiente. }\end{array}$ \\
\hline $\begin{array}{l}\text { O homem como um ser sadio, interagindo no } \\
\text { meio ambiente (ambiente físico, social, } \\
\text { ecossistemas, comunidade). }\end{array}$ & $\begin{array}{l}\text { Levar o aluno a compreensão do homem em constante } \\
\text { interação com o meio ambiente, numa dimensão holística e } \\
\text { ecológica. }\end{array}$ \\
\hline O processo saúde-doença. & $\begin{array}{l}\text { Levar o aluno à compreensão crítica fundamentada nas } \\
\text { necessidades do ser humano sadio e doente, e a adquirir } \\
\text { uma atitude de envolvimento e disponibilidade em relação à } \\
\text { conservação da integridade desse ser humano e a promoção } \\
\text { do seu bem estar. }\end{array}$ \\
\hline O processo político e social da saúde. & $\begin{array}{l}\text { Levar o aluno a uma compreensão crítica e fundamentada } \\
\text { nos problemas de saúde no contexto geral da sociedade } \\
\text { brasileira e a contribuição da enfermagem na visualização } \\
\text { desses problemas. }\end{array}$ \\
\hline Níveis de complexidade das ações do Setor & $\begin{array}{l}\text { Levar o aluno a atuar em situações de elaboração de } \\
\text { diagnósticos simples de saúde de comunidade, realizar ações } \\
\text { de enfermagem, resolver problemas de saúde de baixa } \\
\text { complexidade. }\end{array}$ \\
\hline O processo de educação em saúde. & $\begin{array}{l}\text { Desenvolver no aluno a compreensão do processo de } \\
\text { educação em saúde, evidenciando este processo em si } \\
\text { próprio, enquanto pessoa e iniciando-o nas práticas } \\
\text { elementares em educação e saúde. }\end{array}$ \\
\hline
\end{tabular}

* A consumação destes objetivos no ciclo de formação pré-profissional está prevista para 4 semestres letivos.

\section{QUADRO II - Eixos Integradores e Objetivos do Ciclo Profissional}

\begin{tabular}{||l|l||}
\hline \multicolumn{1}{|c|}{ Eixos Integradores } & \multicolumn{1}{c|}{ Objetivos } \\
\hline A enfermagem como prática social e técnica. & $\begin{array}{l}\text { Levar o aluno a identificar a inserção da prática profissional } \\
\text { no contexto histórico e social, a qual reflete sua atividade } \\
\text { profissional. }\end{array}$ \\
\hline $\begin{array}{l}\text { A prática profissional e a tecnologia para } \\
\text { auxiliar na solução de problemas de saúde. }\end{array}$ & $\begin{array}{l}\text { Facilitar o desenvolvimento de habilidades para solucionar } \\
\text { problemas relativos ao cuidado do indivíduo entendido como } \\
\text { pessoa, membro da família e comunidade. }\end{array}$ \\
\hline $\begin{array}{l}\text { O enfermeiro como membro da equipe de } \\
\text { saúde. }\end{array}$ & $\begin{array}{l}\text { Desenvolver no aluno a capacidade de interagir } \\
\text { adequadamente com os outros elementos integrantes da } \\
\text { equipe de saúde, para o exercício de suas funções } \\
\text { dependentes desses elementos. }\end{array}$ \\
\hline $\begin{array}{l}\text { A prática da enfermagem nas diversas áreas: } \\
\text { Obstétrica, Ginecológica, Pediátrica, }\end{array}$ & $\begin{array}{l}\text { Proporcionar ao aluno uma base científica que fundamenta } \\
\text { os conhecimentos e técnicas especializadas de sua } \\
\text { psofissão, para exercer racionalmente as atividades } \\
\text { independentes que lhe são próprias. }\end{array}$ \\
\hline A prática educativa do enfermeiro. & $\begin{array}{l}\text { Desenvolver no aluno uma atitude de educador a ser } \\
\text { evidenciada tanto em situações formais (treinamento de } \\
\text { pessoal auxiliar, educação em serviço), como em situações } \\
\text { informais/orientação do paciente, família e grupos, quanto } \\
\text { aos cuidados de saúde à população e conscientização desta } \\
\text { para colaborar na manutenção da saúde geral. }\end{array}$ \\
\hline \hline
\end{tabular}




\section{QUADRO III - Eixos Integradores e Objetivos do enfoque de administração no Ciclo Profissional}

\begin{tabular}{||l|l||}
\hline \multicolumn{1}{|c|}{ Eixos Integradores } & \multicolumn{1}{c|}{ Objetivos } \\
\hline Planejamento da assistência à saúde. & $\begin{array}{l}\text { Capacitar o aluno a administrar os serviços de enfermagem } \\
\text { nas diferentes instituições de saúde. }\end{array}$ \\
\hline $\begin{array}{l}\text { Organização, coordenação, execução, } \\
\text { supervisão e avaliação da assistência à } \\
\text { saúde. }\end{array}$ & $\begin{array}{l}\text { Desenvolver atitudes que demonstrem responsabilidade, } \\
\text { liderança, cooperação e respeito a ética profissional. }\end{array}$ \\
\hline $\begin{array}{l}\text { Formação de recursos humanos de } \\
\text { enfermagem. }\end{array}$ & $\begin{array}{l}\text { Colaborar e/ou executar programa de capacidade de } \\
\text { recursos humanos para a saúde. }\end{array}$ \\
\hline \hline
\end{tabular}

\section{Avaliação do Currículo}

A reforma curricular da Escola de Enfermagem de Ribeirão Preto da Universidade de São Paulo, após aprovada pela Congregação da Escola e pela Câmara de Graduação da Universidade de São Paulo, teve sua implantação em 1989.

A avaliação como parte do modelo de planejamento, foi conduzida a partir de alguns indicadores, entendidos como critérios que conduzem a análise de um currículo desde sua implantação. Entendendo-se avaliação, como "Coleta, uso de informação para tomar decisões nas quais ela é utilizada: aperfeiçoamento de cursos, decisão sobre o educando, e regulamentação administrativa ${ }^{9}$.

Os indicadores estabelecidos nesta avaliação foram norteados por três modalidades a diagnóstica, a formativa e a somativa ${ }^{13}$.

A primeira modalidade, a avaliação diagnóstica, caracteriza-se por desenvolver a descrição, classificação e determinação do valor de aspectos de ensino-aprendizagem. Nesta avaliação verificam-se as condições pré-requisitos ou ainda, constatam-se insuficiências, problemas específicos a serem sanados, antes de se instalar o processo de ensino. Neste quadro, para a avaliação do currículo da Escola de Enfermagem de Ribeirão Preto da Universidade de São Paulo, são propostos os seguintes indicadores: perfil do aluno de graduação, política de educação em enfermagem e mercado de trabalho.

A segunda modalidade, avaliação formativa, é a de acompanhamento durante 0 processo de ensino-aprendizagem. Esta identifica e prove elementos para orientar a organização do ensino nas etapas posteriores, através de dados sobre os resultados iniciais. Fornece retroalimentação aos elementos envolvidos no processo ensinoaprendizagem.

Nesta avaliação tem-se levado em consideração os seguintes indicadores: 
- avaliação dos docentes e alunos sobre cada disciplina do curso, ficando esse processo sob responsabilidade dos Departamentos e de suas respectivas disciplinas;

- avaliação dos docentes e alunos, no conjunto de disciplinas de cada semestre, e de sua integração em cada ciclo de formação, sob responsabilidade da Comissão de Graduação.

A terceira modalidade, a avaliação somativa, é a etapa de discussão e julgamento final de um processo. Refere-se à verificação geral do grau em que os resultados foram obtidos. O propósito que a orienta é o de informar os resultados aos alunos, professores e a comunidade em geral. Dessa forma é possível avaliar o produto final elaborado pela Escola, através da proposta de formação do enfermeiro generalista. Entre outros indicadores que tornem possível a obtenção de tais informações a comissão sugere o pretende que se leve a efeito:

- opinião dos alunos egressos da Escola de enfermagem de Ribeirão Preto da Universidade de São Paulo, referente ao currículo cursado e a adequação de sua formação profissional frente à política de saúde atual do país e frente às exigências do mercado de trabalho;

- opiniões de empregadores e chefias de enfermagem quanto a competência do profissional formado pela Escola.

Com a utilização desses indicadores espera-se obter informações sobre a avaliação do profissional, na região de Ribeirão Preto - SP, em duas etapas: a primeira, em 1994 após decorrido um ano de formação da primeira turma de alunos, e a segunda, decorridos cinco anos de formação dessa mesma turma.

Para que haja sucesso na implementação do currículo, e no desenvolvimento no processo de avaliação, a Comissão de Reestruturação Curricular destaca e recomenda alguns pontos fundamentais:

- o processo de implementação do novo currículo deve ter como requisito prévio a participação dos docentes devidamente preparados e qualificados, através de programas de atualização e reciclagem;

- os departamentos deverão estabelecer critérios de avaliação de cada disciplina e do conjunto de disciplinas de cada semestre letivo, através da verificação do alcance dos objetivos gerais do currículo;

- as atividades envolvidas nos processos de avaliação formativa e somativa serão realizadas sob a coordenação dos órgãos colegiados e a participação de docentes e alunos.

\section{IV - Considerações finais}

A necessidade de revisão do ensino e a adequação do currículo de formação profissional à realidade social brasileira e à organização do setor saúde e da própria enfermagem, levou a Escola de Enfermagem de Ribeirão Preto da Universidade de São Paulo 
a uma reflexão analítica de seu currículo, culminando com a proposta de formação do enfermeiro generalista.

Após quase uma década de estudos e reuniões envolvendo docentes e discentes desta Escola, as etapas do planejamento curricular foram alcançadas, com a implantação do currículo em 1989. Tem-se o início de uma nova fase de estudos e da avaliação.

Neste momento a Escola de Enfermagem de Ribeirão Preto da Universidade de São Paulo, se preocupa em avaliar o desempenho de seus docentes e discentes no processo de ensino e na adequação profissional à realidade presente, contribuindo, através destes estudos para o aprimoramento técnico-científico da profissão e para o avanço das atividades de ensino de assistência e da pesquisa na Enfermagem.

The objective of the present study was to describe the process of curricular renovation for the undergraduate Nursing course develop by the Nursing School of Ribeirão Preto, USP, with emphasis on the following planning stage: diagnosis, educational objectives, selection and organization of content, curricular strategies, and curricular evaluation.

In view of a diagnosis of current reality based on a philosophical-pedagogic approach which demonstrates the need to train general duty nurses, we present a conceptual framework directed at the view of man, community, health-sickness process, nursing, general duty nurses, competence, and curriculum. We propose a stronger emphasis on the teaching of biological and human sciences in the basic cycle, as well as on administrative aspects in sanitary and hospital activities. This curriculum covers the cycles of preprofessional and professional training to be offered over eight semesters in the undergraduate Nursing course at EERP-USP.

Este estudio tiene como propósito la descripción del procesos de reforma del Plan de Estudios, en el Curso de Pre-Grado, desenvolvido en la Escola de Enfermagem de Ribeirão Preto de la Universidad de São Paulo, observándose las etapas de planeamiento del Plan de Estudios: el diagnóstico, los objetivos eduacacionales, la selección y organización de contenido, organización estrategias y evaluación del Plan de Estudios.

Frente a un diagnóstico de la realidad vigente, pautado en postura filosófica-pedagógica, que evidencia la necesidad de la formación del enfermero generalista, presentase un cuadro conceptual direccionado a la visión del hombre, comunidad y proceso salud-enfermedad, enfermería, enfermero generalista, competencia y plan de estudio. Se propone el fortalecimiento de la enseñanza de las ciencias biológicas y humanas del ciclo fundamental, así como de los aspectos administrativos en las actividades sanitarias y hospitalares. Ese Plan de Estudios alcanza los ciclos de formación preprofesional a seren ofrecidos en 08 (ocho) semestre del Curso de Pre-Grado. 


\section{REFERÊNCIAS BIBLIOGRÁFICAS}

01.ALMEIDA, M.C.P. Estudo do saber da enfermagem e sua dimensão prática. Rio de Janeiro, 1984. 179p. Tese (Doutorado) Escola Nacional de Saúde Pública da Fundação Oswaldo Cruz.

02. ASSOCIAÇÃO BRASILEIRA DE ENFERMAGEM. Perfil e competência do enfermeiro e o currículo mínimo para a graduação em enfermagem. SEMINÁRIO DA REGIÃO SUDESTE. São Paulo, 17 a 19 de novembro de 1988. Anais. São Paulo, Associação Brasileira de Enfermagem/Escola de Enfermagem da Universidade de São Paulo/EPM, 1988. 106p

03. BRASIL/Conselho Federal de Educação. Parecer 163/72. Currículo mínimo para os cursos de graduação em enfermagem e obstétrica. Brasília, 1972.

04. CARVALHO, V. O ensino de graduação na área da Enfermagem: considerações essenciais e críticas. In: SEMINÁRIO DE ENSINO SUPERIOR DE ENFERMAGEM NORTE-NORDESTE. Recife, 24 a 26 se setembro de 1986. Relatório final, Recife SESV/Ministério da Educação e Cultura/Associação Brasileira de Enfermagem, 1986 p. 19-45.

05. COMISSÃO DE ESTUdOS CURRICULARES DA ESCOLA DE ENFERMAGEM DE RIBEIRÃO PRETO DA UNIVERSIDADE DE SÃO PAULO. Estudos das teorias de enfermagem e sua contribuição aos currículos de graduação. In: Seminário à prática de Enfermagem e o Currículo de Graduação. 1985. Ribeirão Preto. Anais. Ribeirão Preto: Coordenadoria de Atividades Culturais/Escola de Enfermagem de Ribeirão Preto, 1985. p 191-213.

06. COMISSÃO DE ESTUdOS CURRICULARES DA ESCOLA DE ENFERMAGEM DE RIBEIRÃO PRETO DA UNIVERSIDADE DE SÃO PAULO. Relatório sobre os estudos da reforma curricular da Escola de Enfermagem de Ribeirão Preto da Universidade de São Paulo. Ribeirão Preto EERP; 1986. 22 p. (Mimeografado).

07. COMISSÃO DE ESTUDOS CURRICULARES DA ESCOLA DE ENFERMAGEM DE RIBEIRÃO PRETO DA UNIVERSIDADE DE SÃO PAULO. Relatório de conclusão dos estudos sobre a reforma curricular da Escola de Enfermagem de Ribeirão Preto da Universidade de São Paulo. Ribeirão Preto: EERP-USP, 1987 (Mimeografado). 
08. COMISSÃO DE REESTRUTURAÇÃO CURRICULAR DA ESCOLA DE ENFERMAGEM DE RIBEIRÃO PRETO DA UNIVERSIDADE DE SÃO PAULO. O estudo da reformulação curricular da Escola de Enfermagem de Ribeirão Preto da Universidade de São Paulo. Rev.Esc.Enf.USP. São Paulo, v.16, n.21, p. 137-146, ago.1982.

09. CRONBACK, L. Aperfeiçoamento de cursos por meio de avaliação. In: MEESSICK, R.G. (Org.). Currículo: análise e debates. Rio de Janeiro: Zahar, 1980. p. 60-77.

10. FISCHER, T. Currículo de formação profissional. In: O ensino de graduação e melhoria curricular: ciências agrárias. Brasília, Associação Brasileira de Educação Agrícola Superior, outubro, 1984. p.15-30.

11. FREITAS D.M.V. et al. O ensino de graduação em enfermagem EERP-USP, In: FREITAS, D.M.V et. al. Livro comemorativo do $30^{\circ}$ aniversário da EERP-USP. Ribeirão Preto, Ed. Universidade de São Paulo, 1985. p. 44-61.

12. SAUL, A.M. Modelo de pesquisa ação aplicada ao treinamento de professores. São Paulo, 1971. 103 p. Dissertação (Mestrado), Pontifícia Universidade Católica.

13. SPERB, D.C. Problemas gerais de currículo, 2 ed. Porto Alegre: Globo, 1985.

14. TYLER, R. Princípios básicos de currículo e ensino. 5. ed. Porto Alegre, Globo,1978. 


\section{Anexo}

\section{Estrutura curricular de 1992}

Unidade: ESCOLA DE ENFERMAGEM DE RIBEIRÃO PRETO DA UNIVERSIDADE DE SÃO PAULO

\section{Curso: GRADUAÇÃO EM ENFERMAGEM E OBSTETRÍCIA}

\begin{tabular}{|c|c|c|c|c|c|}
\hline $\begin{array}{l}\text { DISCIPLINAS OBRIGATÓRIAS } \\
\text { SEQÜEENCIA ACONCELHADA }\end{array}$ & $\begin{array}{l}\text { REQUISITO } \\
\text { PRÉVIO }\end{array}$ & PARAL. & $\begin{array}{l}\text { CRÉDITOS } \\
\text { AULA }\end{array}$ & TRAB. & $\begin{array}{l}\text { CARGA HORÁRIA } \\
\text { SEMANAL }\end{array}$ \\
\hline \multicolumn{6}{|l|}{$1^{\circ}$ SEMESTRE } \\
\hline $\begin{array}{l}\text { RMF-113 Biologia Celular, Histologia e } \\
\text { embriologia }\end{array}$ & - & RMF-123 & 5 & - & 75 \\
\hline RMF-123 Anatomia Humana & - & - & 7 & - & 105 \\
\hline RBQ-133 Bioquímica & - & - & 6 & - & 90 \\
\hline RPM-143 Microbiologia & - & - & 4 & 1 & 90 \\
\hline $\begin{array}{l}\text { ERM-123 Introdução à Saúde Pública } \\
\text { e Saúde Comunitária }\end{array}$ & - & - & 5 & - & 75 \\
\hline $\begin{array}{l}\text { ERP-100 Histórica e Legislação em } \\
\text { enfermagem }\end{array}$ & - & - & 3 & - & 45 \\
\hline $\begin{array}{l}\text { ERP-113 Integração do Estudante de } \\
\text { Enf. na Esc. e Prof. }\end{array}$ & - & - & 1 & - & 15 \\
\hline \multirow[t]{2}{*}{ Prática Desportiva } & - & - & - & - & 30 \\
\hline & & & 31 & 1 & 525 \\
\hline \multicolumn{6}{|l|}{$2^{\circ}$ SEMESTRE } \\
\hline $\begin{array}{l}\text { ERM-121 Introdução à Estatística } \\
\text { Aplicada à Saúde }\end{array}$ & - & ERM-124 & 4 & - & 60 \\
\hline ERP-110 Psicologia Geral & - & - & 4 & - & 60 \\
\hline ERP-112 Sociologia & - & - & 4 & - & 60 \\
\hline $\begin{array}{l}\text { ERM-124 Introdução à Informática } \\
\text { Aplicada à Saúde }\end{array}$ & - & ERM-121 & 3 & - & 45 \\
\hline $\begin{array}{l}\text { ERM-125 Saneamento e Vigilância } \\
\text { Sanitária }\end{array}$ & $\begin{array}{l}\text { RBQ-133 } \\
\text { RPM-143 } \\
\text { ERM-123 }\end{array}$ & RPM-153 & 3 & - & 45 \\
\hline $\begin{array}{l}\text { ERG-135 Instrumentos Básicos de } \\
\text { Enfermagem }\end{array}$ & - & - & 4 & 1 & 90 \\
\hline RFI-143 Fisiologia & $\begin{array}{l}\text { RMF-113 } \\
\text { RMF-123 }\end{array}$ & - & 8 & - & 120 \\
\hline \multirow[t]{2}{*}{ RPM-153 Parasitologia } & - & - & 3 & - & 45 \\
\hline & & & 33 & 1 & 525 \\
\hline
\end{tabular}




\begin{tabular}{|c|c|c|c|c|c|}
\hline $\begin{array}{l}\text { DISCIPLINAS OBRIGATÓRIAS } \\
\text { SEQÜÊNCIA ACONCELHADA }\end{array}$ & $\begin{array}{l}\text { REQUISITO } \\
\text { PRÉVIO }\end{array}$ & PARAL. & $\begin{array}{l}\text { CRÉDITOS } \\
\text { AULA }\end{array}$ & TRAB. & $\begin{array}{l}\text { CARGA HORÁRIA } \\
\text { SEMANAL }\end{array}$ \\
\hline \multicolumn{6}{|l|}{$3^{\circ}$ SEMESTRE } \\
\hline ERG-217 Introdução à enfermagem & $\begin{array}{c}\text { ERG-135 } \\
\text { ERM-123 } \\
\text { ERP-110 } \\
\text { RFI-143 } \\
\text { RPM-143 } \\
\text { RPM-153 }\end{array}$ & $\begin{array}{l}\text { RFA-233 } \\
\text { ERM-231 }\end{array}$ & 12 & 3 & 270 \\
\hline ERM-231 Nutrição & - & ERG-217 & 3 & - & 45 \\
\hline RGM-223 Genética & RBQ-133 & - & 3 & - & 45 \\
\hline RFA-233 Farmacologia & RFI-143 & - & 6 & - & 90 \\
\hline \multirow[t]{2}{*}{ RPA-233 Patologia } & RFI-143 & - & 2 & 1 & 60 \\
\hline & & & 26 & 4 & 510 \\
\hline \multicolumn{6}{|l|}{$4^{\circ}$ SEMESTRE } \\
\hline ERM-232 Saúde da Criança & $\begin{array}{l}\text { ERM-123 } \\
\text { ERG-217 } \\
\text { ERM-231 }\end{array}$ & ERP-201 & 6 & 1 & 120 \\
\hline ERM-233 Saúde da Mulher & $\begin{array}{l}\text { ERM-123 } \\
\text { ERG-217 }\end{array}$ & - & 6 & 1 & 120 \\
\hline ERM-234 Saúde do Adulto & $\begin{array}{l}\text { ERM-231 } \\
\text { ERG-217 }\end{array}$ & - & 6 & 1 & 120 \\
\hline $\begin{array}{l}\text { ERP-200 Enfermagem Psiquiátrica } \\
\text { Preventiva }\end{array}$ & - & ERP-201 & 3 & 1 & 75 \\
\hline $\begin{array}{l}\text { ERP-202 Didáticos I (Introdução à } \\
\text { Didática) }\end{array}$ & - & - & 2 & - & 30 \\
\hline ERP-203 Ética Fundamental & - & - & 1 & - & 15 \\
\hline \multirow[t]{2}{*}{$\begin{array}{l}\text { ERP-201 Psicologia do } \\
\text { Desenvolvimento }\end{array}$} & ERP-110 & $\begin{array}{l}\text { ERM-232 } \\
\text { ERM-233 } \\
\text { ERM-234 }\end{array}$ & 1 & - & 15 \\
\hline & & & 25 & 4 & 495 \\
\hline \multicolumn{6}{|l|}{$5^{\circ}$ SEMESTRE } \\
\hline ERG-310 Enfermagem Médica & $\begin{array}{l}\text { RPA-233 } \\
\text { RFA-233 } \\
\text { ERG-217 } \\
\text { ERP-202 } \\
\text { ERM-234 }\end{array}$ & ERM-320 & 11 & 3 & 255 \\
\hline $\begin{array}{l}\text { ERG-345 Enfermagem em Doenças } \\
\text { Transmissíveis }\end{array}$ & $\begin{array}{l}\text { RPA-233 } \\
\text { RFA-233 } \\
\text { ERG-217 } \\
\text { ERM-125 } \\
\text { ERM-234 }\end{array}$ & $\begin{array}{l}\text { ERG-310 } \\
\text { ERM-319 } \\
\text { ERM-320 }\end{array}$ & 4 & - & 60 \\
\hline $\begin{array}{l}\text { ERP-301 Estudos de Problemas } \\
\text { Brasileiros }\end{array}$ & - & - & 1 & - & 15 \\
\hline ERM-320 Dietoterapia & ERM-231 & ERG-310 & 2 & - & 30 \\
\hline $\begin{array}{l}\text { ERG-333 Introdução à Administração } \\
\text { Aplicada à Enfermagem }\end{array}$ & - & - & 4 & - & 60 \\
\hline
\end{tabular}




\begin{tabular}{|c|c|c|c|c|c|}
\hline $\begin{array}{l}\text { DISCIPLINAS OBRIGATÓRIAS } \\
\text { SEQÜÊNCIA ACONCELHADA }\end{array}$ & $\begin{array}{l}\text { REQUISITO } \\
\text { PRÉVIO }\end{array}$ & PARAL. & $\begin{array}{l}\text { CRÉDITOS } \\
\text { AULA }\end{array}$ & TRAB. & $\begin{array}{l}\text { CARGA HORÁRIA } \\
\text { SEMANAL }\end{array}$ \\
\hline \multicolumn{6}{|l|}{$5^{\circ}$ SEMESTRE (continuação) } \\
\hline $\begin{array}{l}\text { ERM-319 Epidemiologia e Vigilância } \\
\text { Epidemiológica }\end{array}$ & $\begin{array}{l}\text { ERM-121 } \\
\text { ERM-123 } \\
\text { ERM-125 }\end{array}$ & - & 4 & 1 & 90 \\
\hline \multirow{2}{*}{$\begin{array}{l}\text { ERP-202 Didática I (Introdução à } \\
\text { Didática) }\end{array}$} & - & - & 2 & - & 30 \\
\hline & & & 28 & 4 & 540 \\
\hline \multicolumn{6}{|l|}{$6^{\circ}$ SEMESTRE } \\
\hline ERG-360 Enfermagem Cirúrgica & $\begin{array}{l}\text { RFA-233 } \\
\text { RPA-233 } \\
\text { ERM-234 } \\
\text { ERG-333 }\end{array}$ & - & 12 & 4 & 300 \\
\hline $\begin{array}{l}\text { ERG-350 Introdução à Enfermagem do } \\
\text { Trabalho }\end{array}$ & $\begin{array}{l}\text { ERG-217 } \\
\text { ERM-319 } \\
\text { ERP-202 }\end{array}$ & - & 1 & 1 & 45 \\
\hline \multirow[t]{2}{*}{ ERP-300 Enfermagem Psiquiátrica } & $\begin{array}{l}\text { ERP-200 } \\
\text { ERM-201 }\end{array}$ & - & 8 & 2 & 180 \\
\hline & & & 21 & 7 & 525 \\
\hline \multicolumn{6}{|l|}{$7^{\circ}$ SEMESTRE } \\
\hline ERM-421 Enfermagem Pediátrica & $\begin{array}{l}\text { ERM-232 } \\
\text { ERG-310 } \\
\text { ERG-345 }\end{array}$ & ERP-402 & 6 & 2 & 150 \\
\hline $\begin{array}{l}\text { ERM-422 Enfermagem Obstétrica e } \\
\text { Ginecológica }\end{array}$ & $\begin{array}{l}\text { ERM-233 } \\
\text { ERG-360 }\end{array}$ & - & 8 & 2 & 180 \\
\hline ERP-403 Ética em Enfermagem & - & - & 2 & - & 30 \\
\hline ERP-400 Didática II (Didática Aplicada) & ERP-202 & - & 2 & 1 & 60 \\
\hline ERP-402 Psicologia II & ERP-201 & ERM-421 & 1 & - & 15 \\
\hline \multirow{2}{*}{$\begin{array}{l}\text { ERP-401 Estudo de Problemas } \\
\text { Brasileiros }\end{array}$} & - & - & 1 & - & 15 \\
\hline & & & 20 & 5 & 450 \\
\hline \multicolumn{6}{|l|}{$8^{\circ}$ SEMESTRE } \\
\hline $\begin{array}{l}\text { ERP-301 Estudo de Problemas } \\
\text { Brasileiros }\end{array}$ & - & - & 1 & - & 15 \\
\hline $\begin{array}{l}\text { ERM-423 Administração de } \\
\text { Enfermagem em Unidade }\end{array}$ & $\begin{array}{l}\text { ERG-333 } \\
\text { ERM-421 } \\
\text { ERM-422 }\end{array}$ & ERP-404 & 7 & 4 & 225 \\
\hline $\begin{array}{l}\text { ERG-477 Administração Aplicada à } \\
\text { Enfermagem Hospitalar }\end{array}$ & $\begin{array}{l}\text { ERG-333 } \\
\text { ERP-403 } \\
\text { ERM-421 } \\
\text { ERM-422 }\end{array}$ & ERP-404 & 9 & 3 & 225 \\
\hline \multirow[t]{2}{*}{$\begin{array}{l}\text { ERP-404 Dinâmica das Relações em } \\
\text { Grupo na Enfermagem }\end{array}$} & $\begin{array}{l}\text { ERP-201 } \\
\text { ERG-333 }\end{array}$ & $\begin{array}{l}\text { ERM-423 } \\
\text { ERG-477 }\end{array}$ & 2 & 1 & 60 \\
\hline & & & 19 & 8 & 525 \\
\hline
\end{tabular}

